\title{
Pulmonary Artery Catheter Knotting and its Successful Removal.
}

\author{
${ }^{1}$ Ayaskant Sahoo, ${ }^{1}$ Mohammad Omar Shah, ${ }^{2}$ Rakesh M Gangadhar, \\ ${ }^{3}$ Harish R Nair ${ }^{4}$ M.SMoosabba, ${ }^{5}$ S Padmanabha, ${ }^{6}$ Narasimha Pai \\ ${ }^{1}$ Post graduate, Yenepoya Medical college, Yenepoyauniversity, Mangalore, Karnataka \\ ${ }^{2}$ Cardiac Anaesthesiologist, Yenepoya Specialty Hospital, Mangalore, Karnataka \\ ${ }^{3}$ Cardiothoracic Surgeon, Yenepoya Medical college, Yenepoya university, Mangalore, Karnataka \\ ${ }^{4}$ Superintendent and HOD, Department of Surgery, Yenepoya Medical college, Yenepoya university, Mangalore, Karnataka \\ ${ }^{5}$ Professor and HOD, Department of Anaesthesia and Critical care, Yenepoya medical college, Yenepoyauniversity, \\ Mangalore, Karnataka. \\ ${ }^{6}$ Cardiologist, Yenepoya Specialty Hospital, Mangalore, Karnataka
}

\begin{abstract}
Pulmonary artery catheter(PAC) was introduced by Swan Ganz and colleagues in 1970 for hemodynamic assessment of patients with acute myocardial infarction. PAC's provide invasive monitoring of many hemodynamic parameters which cannot be reliably estimated by clinical signs and symptoms. Use of PAC's is associated with many different complications and various studies have been done to weigh its advantages and disadvantages. Here we report one of the rarer complications of PAC knotting and its method of removal.
\end{abstract}

Keywords:Pulmonary artery catheter, Knot,

\section{Introduction:}

A 60years old female patient suffering from a triple vessel coronary artery disease was posted for coronary artery bypass graft. The patient weighed $74 \mathrm{~kg}$ and was $151 \mathrm{~cm}$ in height. Preoperative ECHO showed hypokinesia of interventricular septum and ejection fraction of approximately $35 \%$. Intraoperativelymonitoring was used using radial(left) and femoral arterial(right) lines, pulmonary artery catheter and transesophageal echocardiography. Surgery was uneventfula and patient was shifted to ITU. All invasive monitoring lines were kept in-situ on the day of surgery. After patient was hemodynamically stable, attempt was made to remove the pulmonary artery catheter but we faced resistance even after 2-3attempts. At this point a knotting of the catheter was suspected. The chest X-Ray was revisited and upon closer looking confirmed the knotting. Attempt was made to release the knot by inserting a guidewire but failed. Patient was then shifted to cath-lab and help was sought from an interventional cardiologist due to unavailability of an interventional radiologist. The PAC was approached through the femoral vein and the catheter was cut just above the knot. The upper cut part was removed by simply pulling out through the internal jugular vein. The lower cut part was pulled and brought upto the femoral vein and with a small incision on the femoral vein the knotted part was removed and the vein was immediately repaired.

\section{Discussion:}

Indications of $\mathrm{PAC}^{1}$ :

1. Severe left ventricular dysfunction

2. Severe pulmonary dysfunction

3. Severe pulmonary hypertension

4. Septic shock

5. Cardiogenic shock

6. Pulmonary edema

7. Severe toxaemia of pregnancy

Complications of PAC use has been reported to be about $24 \%{ }^{2}$ in

1. Pulmonary artery or Right atrium rupture

2. Venous access complications like carotid artery puncture

3. Entrapment in sutures during cardiac surgery ${ }^{3}$

4. Dysrhythmias following PAC insertion most commonly premature ventricular and atrial ectopics PAC's are more likely to get knotted than other intravascular catheters owing to their length and thin flexible walls ${ }^{4}$. The pulmonary artery catheter knotting is reported to be only $0.03 \%$ of all reported complications of PAC.

The various techniques that has been described are usually classified as surgical or non surgical,Via cardiotomy ${ }^{5}$, Interventional radiological techniques, 0.038 inch movable core-guided wire through the lumen of the catheter to untie the knot under fluoroscopic guidance, removal using snare, open surgery, etc ${ }^{6,7,8}$ 


\section{Conclusion:}

Pulmonary artery catheters provide essential hemodynamic measurements both in operation theatres as well as in ICU set up but many a times debated about the associated morbidity and mortality, various studies claim various percentages of problems but its application or importance cannot be undermined. The clinician should always keep in mind the associated complications and try to avoid them by utilizing the available information regarding the successful application.

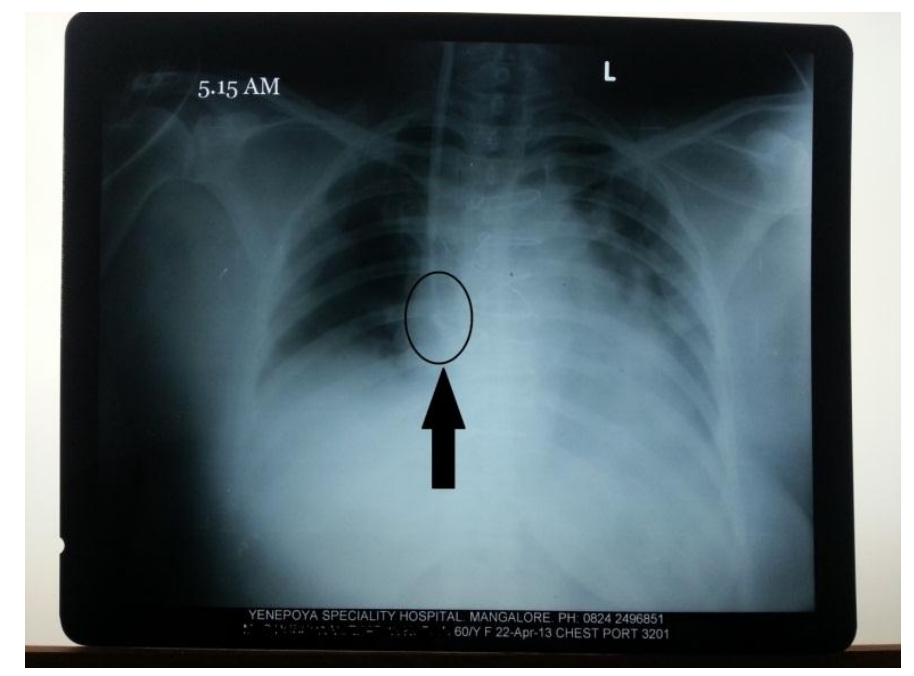

Picture 1.

Picture showing the knot on Chest X-Ray

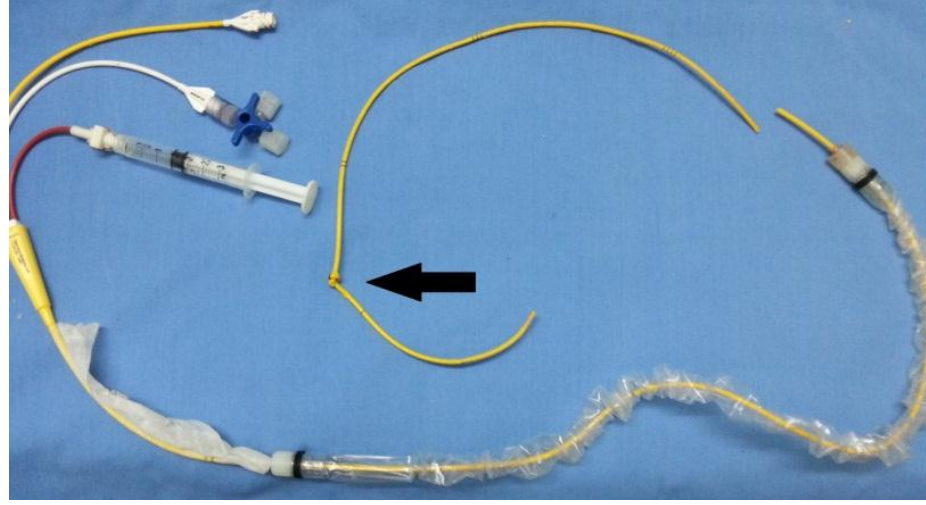

Picture 2.The knotted catheter after extraction. The knot is shown by an arrow.

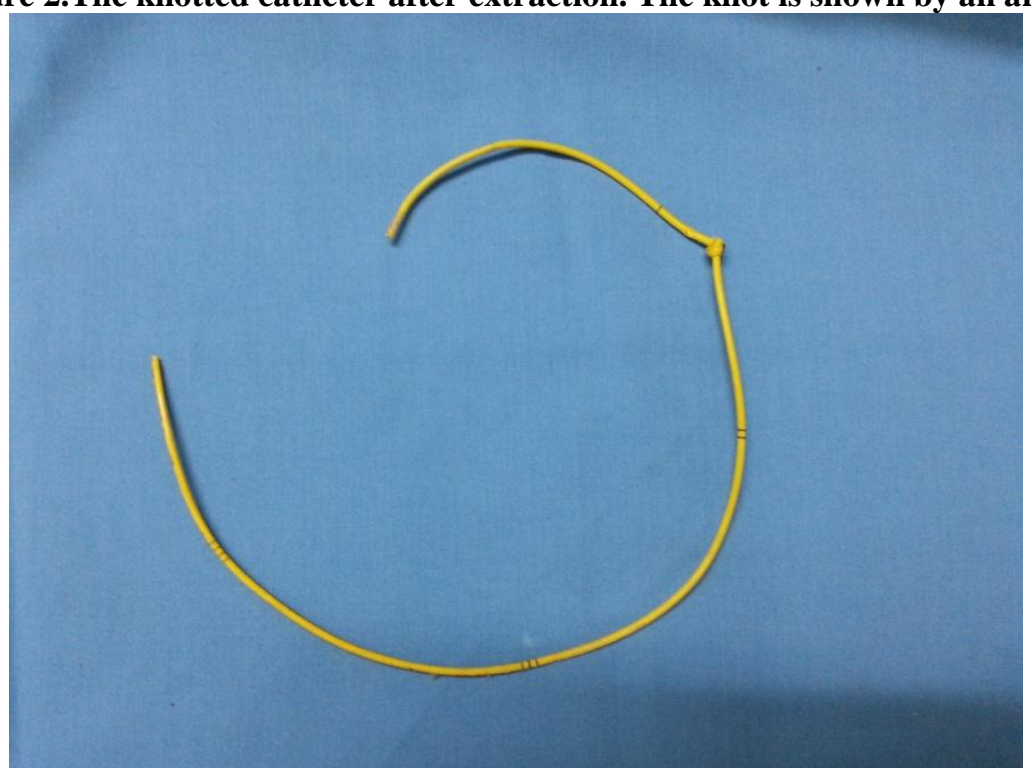

Picture 3.The shorter cut portion of the PAC that was pulled out through the sheath in neck through IJV. 


\section{References:}

[1]. Lopes MC, de Cleva R, Zilberstein B, Gama-Rodrigues JJ. Pulmonary artery catheter complications: report on acase of a knot accident and literature review. Rev HospClinFac Med Sao Paulo. 2004;59(2):77-85.

[2]. Boyd KD, Thomas SJ, Gold J, Boyd AD. A prospective study of complications of pulmonary artery catheterizations in 500 consecutive patients. Chest. 1983;84(3):245-249.

[3]. Huang L, Elsharydah A, Nawabi A, Cork RC. Entrapment of pulmonary artery catheter in a suture at the inferior vena cava cannulation site. J ClinAnesth. 2004;16:557-559.

[4]. Eshkevari L, Baker BM. Occurrence and removal of a knotted pulmonary artery catheter a case report. AANA J. 2007;75:423-8.

[5]. Kao MC, Lin SM, Yu YS, Huang YC, Ting CK, Tsai SK. Knotted continuous cardiac output cardiac output thermodilution catheter diagnosed by intraoperative transesophageal echocardiography. Br J Anaesth. 2003;91:451-452

[6]. England MR, Murphy HI, Yakirevich V, Vidne B. A knotty problem. J Cardiothoracic VascAnesth. 1997;11:682-683

[7]. Colbert S, O'Hanlon DM, Quill DS, Keane P. Swan Ganz catheter- all in a knot. Eur J Anaesthesiol. 1997;14:518-520

[8]. Tan C, Bristol PJ, Segal P, Bell RJ: A technique to remove knotted pulmonary artery catheters. Anaesth Interns Care. 1997;25:160162 